\title{
Disease Management Strategy for Direct and Immediate Implementation of Artificial Intelligence-Based MRI in Radiology
}

\author{
Laura Fanea \\ Department of Radiology, Cluj County Emergency Hospital, Cluj-Napoca, Romania \\ Email: laura.fanea@gmail.com
}

How to cite this paper: Fanea, L. (2019) Disease Management Strategy for Direct and Immediate Implementation of Artificial Intelligence-Based MRI in Radiology. Journal of Biosciences and Medicines, 7, 38-50.

https://doi.org/10.4236/jbm.2019.79005

Received: July 29, 2019

Accepted: August 31, 2019

Published: September 3, 2019

Copyright $\odot 2019$ by author(s) and Scientific Research Publishing Inc. This work is licensed under the Creative Commons Attribution International License (CC BY 4.0).

http://creativecommons.org/licenses/by/4.0/

\begin{abstract}
Background: Artificial intelligence (AI) implementation in medicine will increase the efficiency of medical services. Objective: To develop a disease management strategy for the direct and immediate implementation of AI MRI in radiology. Methods: Correlations between selected quantitative MRI parameters available in the literature and the corresponding physio-anatomy were made to build the human MRI physio-anatomical state chart (hMRI_PASC). Pathology can be assessed using the relative-to-normal (RN) values of each MRI parameter for corresponding control-normal $(\mathrm{CN})$ and disease-affected (DA) regions, based on the equation: RN_Parameter(\%) = multiply $\left(100\right.$, divide(subtract $\left(\right.$ Parameter $_{\mathrm{DA}}$, Parameter $\left._{\mathrm{CN}}\right)$, (Parameter $\left.\left.\mathrm{P}_{\mathrm{CN}}\right)\right)$ ). The 50\% RN_Parameter absolute value threshold for the selected MRI parameters was used to define a medical condition severity staging scale (MCSSS). The disease management strategy is presented for a scenario of DA human MRI organ model: the eye, using the hMRI_PASC, and MCSSS. Results: Inflammation, constriction, stiffness, and/or infiltration of blood or T1 and/or T2 lengthening or shortening agents, macromolecules, calcifications, and iron particles through broken blood vessels or broken blood vessels and blood-to-tissue barriers can be assessed based on the hMRI_PASC. Three levels: infiltration, dynamics and elastography (IDE), seven types, and eighteen stages are defined in the MCSSS. The disease management strategy introduced in this study shows that integrity of the seven affected ocular regions could be regained through therapeutical intervention, possibly followed by surgery targeted to one of the affected ocular regions. Conclusion: The hMRI_PASC, MCSSS, and disease management strategy presented in this study can be implemented immediately and directly in a software for AI-based MRI.
\end{abstract}




\section{Keywords}

Radiology, Magnetic Resonance Imaging, Artificial Intelligence, Radiomics

\section{Introduction}

Artificial intelligence (AI) is considered the third eye for medical specialists and has a promising perspective field for medical imaging [1], offering the most complex and accurate information to patients and medical specialists in the most rapid way through the most performance of medical evaluations [2] [3] [4] [5] [6]. AI-based imaging is needed to reduce the socio-economical burden caused by disease and improve the efficiency in radiology departments.

The current situation of AI in medical imaging has been analysed recently and the future directions have been suggested [2]. Wandell et al., 2016 [6], 2015 [7] [8], Benson et al., 2012 [9], 2014 [10], 2018 [11], 2019 [12], Jiang et al., 2017 [13], and Dumoulin et al., 2008 [14], 2017 [15] have already made some steps in these directions and developed complex AI algorithms for image analyses. Strategies for data management to support reproducible research [16], the influence of feedback in intelligence processes [17], and algorithms for more rapid MRI data acquisition [18] were also evaluated. Many AI developments are suitable for MRI [19] due to the wealth of qualitative and quantitative pathophysiological information offered for any organ in the human body and the low imaging invasiveness [20]. The brain [6] [8] [14] [15] [21] [22], prostate [23] [24] [25] [26], heart [27] [28], breast [29], and eye [20] [30] [31] are the human organs most frequently evaluated using multiparametric MRI in recent years. Software developers need basic specifications for explainable MRI to implement these developments in AI-based clinical radiology. Specifications for explainable MRI were obtained from complex correlations between the geometrico-physicochemical MRI parameters and the corresponding pathophysiology to evaluate the rat brain [32]. A generalisation of this approach combined with the already available clinical AI-based strategies for medical diagnosis in dermatology [33] and cardiology [34] was made to assess the clinical MRI data available in the literature and develop the human MRI physio-anatomical state chart (hMRI_PASC) and the medical condition severity staging scale (MCSSS) for AI-based disease management. These results can be introduced directly and immediately in a software for AI-based clinical ocular MRI.

The objective of this study was to introduce the basic specifications for explainable MRI: hMRI_PASC and MCSSS for AI-based disease management. These specifications were obtained from complex correlations between the geometrico-physicochemical MRI parameters calculated in the literature and the corresponding human pathophysiology. The specifications for explainable clinical MRI were organised in the structured hMRI_PASC and MCSSS. The eye was selected as an MRI human organ model [20] to explain the strategy proposed for 
future AI-based disease management, using the hMRI_PASC and MCSSS. The ocular MRI scenario presented and analysed shows that extremely complex medical information can be achieved using the results in this study.

The hMRI_PASC and MCSSS developed in this study can be introduced directly and immediately in a software for AI-based clinical ocular MRI. The disease management strategy presented and analysed also demonstrates that AI-based MRI medical diagnosis is ready to be implemented in radiology, ophthalmology, and/or medicine. Future studies involving other imaging techniques are needed to generalise these results for AI-based diagnosis, prognosis, therapy and/or surgery implementation in radiology and medicine.

\section{Methods}

MRI parameters assessed in statistical radiomic studies to date [20]-[37] were selected. These were grouped based on the general characteristic bio-physiological effect evaluated quantitatively and included in this study (Table 1). For each MRI parameter in Table 1, a relative-to-normal ( $\mathrm{RN}$ ) value was introduced

Table 1. Quantitative MRI parameters. The name, symbol, and measurement unit of the geometrico-physicochemical MRI parameters used in this study to assess the human pathophysiology [20]-[37] are presented below. The effects evaluated using the quantitative MRI techniques at present are also specified.

\begin{tabular}{|c|c|c|c|c|c|}
\hline \multirow{2}{*}{ Effect } & \multirow{2}{*}{ Technique } & \multicolumn{4}{|l|}{ Parameter } \\
\hline & & Name & Symbol & Unit & Type \\
\hline \multirow{9}{*}{ Infiltration } & \multirow{3}{*}{ Relaxometry } & $\mathrm{T} 1$ relaxation time & $\mathrm{T} 1$ & \multirow{2}{*}{$\mathrm{ms}$} & physico- \\
\hline & & $\mathrm{T} 2$ relaxation time & $\mathrm{T} 2$ & & chemical \\
\hline & & spin density & M0 & $\%$ & chemical \\
\hline & \multirow{3}{*}{$\begin{array}{l}\text { Magnetisation } \\
\text { transfer }\end{array}$} & $\begin{array}{l}\text { magnetisation transfer } \\
\text { ratio }\end{array}$ & $\mathrm{R}$ & $\%$ & physical \\
\hline & & macromolecular volume & $\mathrm{V}$ & $\mathrm{mm}^{3}$ & geometrical \\
\hline & & $\begin{array}{l}\text { macromolecular } \\
\text { concentration }\end{array}$ & $\mathrm{C}$ & $\%$ & chemical \\
\hline & \multirow{3}{*}{$\begin{array}{l}\text { Susceptibility } \\
\text { weighted }\end{array}$} & magnetic susceptibility & $\mathrm{X}$ & no dimension & \multirow{2}{*}{ physical } \\
\hline & & magnetic permeability & $\mathrm{P}$ & $\mathrm{H} / \mathrm{m}$ & \\
\hline & & iron concentration & I & $\mathrm{mmol} / \mathrm{g}$ & chemical \\
\hline \multirow{5}{*}{ Dynamics } & \multirow{3}{*}{ Diffusion } & diffusion coefficient & $\mathrm{D}$ & $\mathrm{mm}^{2} / \mathrm{s}$ & physical \\
\hline & & anisotropy & A & no dimension & $\begin{array}{l}\text { geometrical \& } \\
\text { physical }\end{array}$ \\
\hline & & fractional volume & $\mathrm{V}$ & $\%$ & geometrical \\
\hline & \multirow[t]{2}{*}{ Flow } & volume & $\mathrm{V}$ & $\begin{array}{l}\mathrm{ml} \text { (blood)/ } \\
\text { 100g (tissue) }\end{array}$ & geometrical \\
\hline & & flow & $\mathrm{f}$ & $\mathrm{ml} / \mathrm{g} / \mathrm{min}$ & physical \\
\hline \multirow{4}{*}{ Elastography } & \multirow{3}{*}{ Any } & thickness & $\mathrm{T}$ & $\mathrm{mm}$ & \multirow{3}{*}{ geometrical } \\
\hline & & area & $\mathrm{A}$ & $\mathrm{mm}^{2}$ & \\
\hline & & volume & $\mathrm{V}$ & $\mathrm{mm}^{3}$ & \\
\hline & Elastography & stiffness & $\mathrm{S}$ & $\mathrm{kPa}$ & physical \\
\hline
\end{tabular}


for any corresponding disease-affected (DA) and control-normal (CN) anatomical region-of-interest to assess severity of a medical condition based on the procentual difference between corresponding DA and CN anatomical regions, using the equation: RN_Parameter(\%) = multiply(100, divide(subtract (Parame-

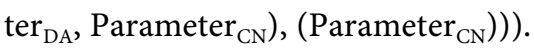

Modifications relative to the corresponding $\mathrm{CN}$ anatomical region in this study were signaled by positive or negative RN_Parameter values. The RN_Parameter threshold absolute value for disease detection was set up to 50\% in this study. The $>$, and < symbols were used for the RN_Parameter values over $50 \%$ or below $-50 \%$, respectively.

The correlations between each possible RN_Parameter value and the corresponding physio-anatomy were made to define the hMRI_PASC (Table 2). An MCSSS for AI-based MRI (Figure 1) was also proposed based on each possible RN_Parameter value in Table 1 .

The disease management strategy for AI-based MRI is presented for a scenario applied to a human body organ MRI model: the eye [20]. The ocular regions assessed using the results in this study are presented in Figure 2. The finest $\mathrm{CN}$ human eye anatomy visualised on an MRI slice was achieved at 3 T MRI [20] and consists of: cornea, iris, ciliary body, aqueous humour, lens, vitreous humour, sclera, optic nerve, and three layers in the retina-choroid complex region [20] [38] as presented in Figure 2(a). An example of DA eye with visibly inflamed iris and ciliary body, and deformed lens and aqueous humour is shown in Figure 2(b). The regions in Figure 2(c) show the selections used for the quantitative assessment of the MRI parameters presented in Table 1.

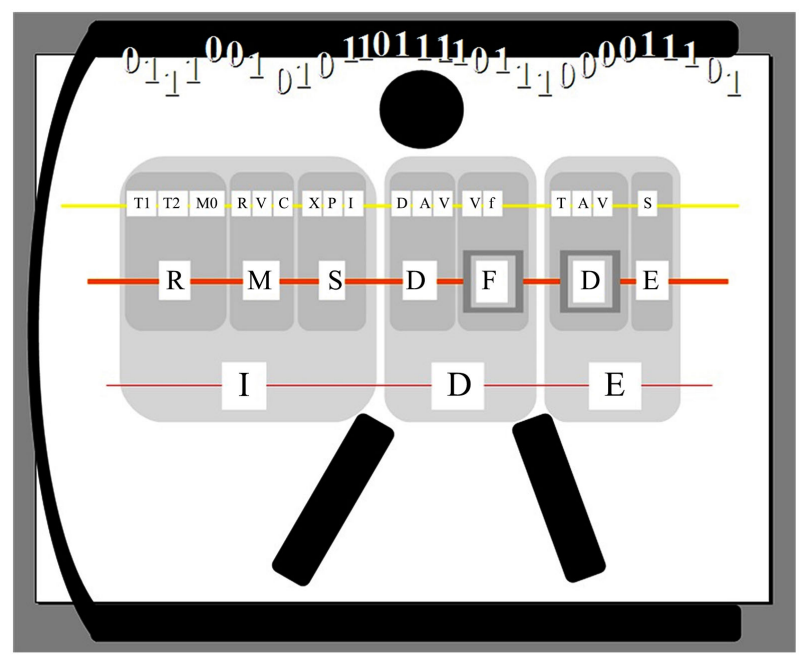

Figure 1. MRI staging scale for future AI-based MRI disease management. The levels, types and stages were defined based on the general available MRI findings to date [20]-[37]. The letters are arranged along straight lines representing levels, types, and stages. Thickness of the straight lines increases from levels to stages. The rainbow colours are used in combination with the variable thickness for each straight line. The rectangular light and dark gray borders represent dynamic and dynamic susceptibility contrast enhancement, respectively. Letters without borders are used for unenhanced types. 


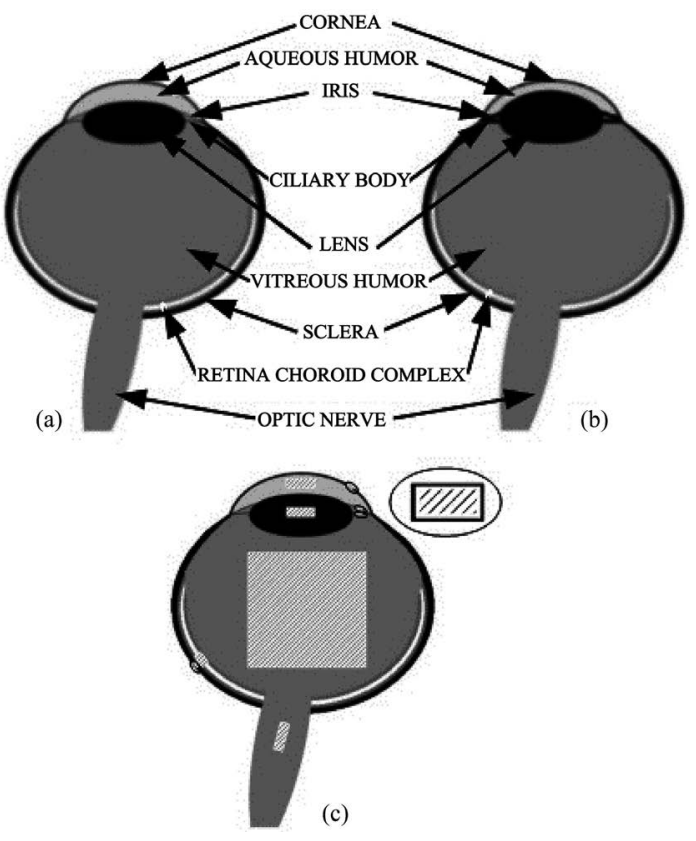

Figure 2. High resolution MRI of the human eye. The normal human eye structures visualised at present using MRI [20] [30] [31] [38] are shown in (a). An example of human ocular MRI pathology detected using MRI is also presented in (b). In (b), deformation of the lens and aqueous humour and inflammation of the iris and ciliary body are shown. The regions-of-interest for the quantitative eye MRI assessment from current literature [20] [30] [31] are presented in (c).

Table 2. Human physio-anatomical MRI state chart. The corresponding physio-anatomical state for each possible RN_Parameter value in Table 1 is presented below. The symbols: $0,>$, and < stand for absolute differences between corresponding DA and CN RN_Parameter absolute values: smaller $(0)$, and larger $(>$, and $<$ ) than the $50 \%$ threshold value. $>$, and $<$ were used to symbolise RN_Patameter values over and below the $50 \%$ and $-50 \%$ threshold, respectively.

\begin{tabular}{|c|c|c|c|c|}
\hline \multirow{2}{*}{ Level } & \multirow{2}{*}{$\begin{array}{l}\text { RN MRI } \\
\text { Parameter }\end{array}$} & \multicolumn{3}{|c|}{ MRI physio-anatomical state chart } \\
\hline & & 0 & $>$ & $<$ \\
\hline \multirow[t]{3}{*}{ Infiltration } & $\begin{array}{l}\text { T1, T2, R, } \\
\text { V, C, X, P, I }\end{array}$ & $\begin{array}{l}\text { no T1, T2, } \\
\text { macromolecular, } \\
\text { calcification-specific, } \\
\text { iron-based agent }\end{array}$ & $\begin{array}{l}\text { blood or T1-, T2-, R-, } \\
\text { X-, P-, I-lengthening } \\
\text { substance infilitration } \\
\text { through broken blood } \\
\text { vessels }\end{array}$ & $\begin{array}{l}\text { T1-, T2-, R-, X-, P-, } \\
\text { I-shortening substance } \\
\text { infiltration through } \\
\text { broken blood vessels and } \\
\text { blood-to-tissue barrier }\end{array}$ \\
\hline & $\mathrm{D}$ & $\begin{array}{l}\text { no diffusion changes } \\
\text { of } 1 \mathrm{H} \text { nuclei in water } \\
\text { molecules }\end{array}$ & $\begin{array}{l}\text { faster diffusing } 1 \mathrm{H} \\
\text { nuclei in water } \\
\text { molecules }\end{array}$ & $\begin{array}{l}\text { slower diffusing } 1 \mathrm{H} \text { nuclei } \\
\text { in water molecules }\end{array}$ \\
\hline & A & $\begin{array}{l}\text { same degree of } \\
\text { diffusion anisotropy }\end{array}$ & $\begin{array}{l}\text { increased degree of } \\
\text { diffusion anisotropy }\end{array}$ & $\begin{array}{l}\text { decreased degree of } \\
\text { diffusion anisotropy }\end{array}$ \\
\hline \multirow[t]{2}{*}{ Dynamics } & $\mathrm{V}$ & $\begin{array}{l}\text { no volume changes } \\
\text { of the diffusing } \\
\text { component }\end{array}$ & $\begin{array}{l}\text { increased volume } \\
\text { of the diffusing } \\
\text { component }\end{array}$ & $\begin{array}{l}\text { decreased volume of the } \\
\text { diffusing component }\end{array}$ \\
\hline & $\mathrm{V}, \mathrm{f}$ & $\begin{array}{l}\text { no flow (volume, rate) } \\
\text { changes of } 1 \mathrm{H} \text { nuclei } \\
\text { in water molecules }\end{array}$ & $\begin{array}{l}\text { increased flow } \\
\text { (volume, rate) of } 1 \mathrm{H} \\
\text { nuclei in water } \\
\text { molecules }\end{array}$ & $\begin{array}{l}\text { decreased flow (volume, } \\
\text { rate) of } 1 \mathrm{H} \text { nuclei in water } \\
\text { molecules }\end{array}$ \\
\hline \multirow{2}{*}{ Elastography } & $\mathrm{T}, \mathrm{A}, \mathrm{V}$ & no inflammation & inflammation & constriction \\
\hline & S & same stiffness & increased stiffness & decreased stiffness \\
\hline
\end{tabular}




\section{Results}

The specifications relevant for the diagnosis of a medical condition detected are presented in the hMRI_PASC in Table 2. The IDE MCSSS presented in Figure 1 was used to detect bio-physiological changes in the regions-of-interest, produced by: external agent infiltration, changes in the dynamics of the $1 \mathrm{H}$ nuclei in water molecules, and/or elastic deformations. Infiltration of blood or T1 and/or T2 lengthening or shortening agents, macromolecules, calcifications, and iron particles through broken blood vessels or broken blood vessels and blood-to-tissue barriers can be detected using MRI. The dynamics of the $1 \mathrm{H}$ nuclei in water molecules can be assessed with diffusion [39] and flow sensitive [35] MRI techniques applied to different regions of the human body. Inflammation, constriction or stiffness of regions can be detected in MRI elastography studies [37]. The geometrico-physicochemical parameters in Table 1 were used to analyse the physiological IDE status of a region-of-interest based on the hMRI_PASC in Table 2.

According to Figure 1, severity of a medical condition can be classified in 3 levels, 7 types, and 18 stages. The 3 levels are: infiltration (I), dynamics (D), and elastography (E), IDE. The I, D, and E levels are of 3, 2, and 2 types, respectively. The 7 severity types are: I relaxometry: I(R), I magnetisation transfer: I(M), I susceptibility-weighted: $\mathrm{I}(\mathrm{S}), \mathrm{D}$ diffusion: $\mathrm{D}(\mathrm{D}), \mathrm{D}$ flow: $\mathrm{D}(\mathrm{F}), \mathrm{E}$ dimension: $E(D)$, and E elastography: $E(E)$. The level types $D(F)$ and $E(D)$ can be: unenhanced, dynamic or dynamic susceptibility contrast agent enhanced, represented by: non-, light, and dark gray highlighted terms, respectively. Each level type has different stages: $\mathrm{I}(\mathrm{R}(\mathrm{T} 1, \mathrm{~T} 2, \mathrm{M} 0)), \mathrm{I}(\mathrm{M}(\mathrm{R}, \mathrm{V}, \mathrm{C})), \mathrm{I}(\mathrm{S}(\mathrm{X}, \mathrm{P}, \mathrm{I})), \mathrm{D}(\mathrm{D}(\mathrm{D}, \mathrm{A}, \mathrm{V}))$, $\mathrm{D}(\mathrm{F}(\mathrm{V}, \mathrm{f})), \mathrm{E}(\mathrm{D}(\mathrm{T}, \mathrm{A}, \mathrm{V}))$, and $\mathrm{E}(\mathrm{E}(\mathrm{S}))$, depending on the number of the MRI parameters calculated.

The total number of general MRI parameters in this study is 18 and this also represents the number of IDE stages.

The general configuration of the MCSSS in Figure 1 is:

Level(Type(Subtype(Stage(RN_Parameter value) or Stage(RN_Parameter value)))). The first configuration is for positive RN_Parameter values, while the underlined Stage(RN_Parameter value) configuration corresponds to negative values.

For the worse case scenario, let's assume that in an MRI study, all the parameters presented in Figure 1 were calculated and each of these parameters had the positive or negative RN_Parameter values from v1 to v18. The configuration of such a situation is:

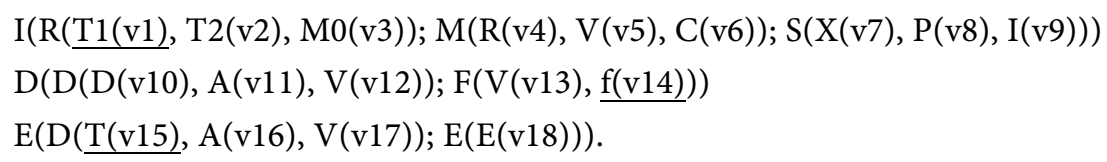

The $\underline{\mathrm{T} 1(\mathrm{v} 1)}$ and $\underline{\mathrm{T}(\mathrm{v} 15)} \mathrm{RN}$.Parameter values are negative and these were calculated using unenhanced and dynamic contrast enhanced MRI, respectively. Dynamic susceptibility contrast enhanced MRI was used to calculate the positive FV(v13) and negative Ff(v14) RN_Parameter values. 
The first letter in the MCSSS configuration represents the level of the disease, corresponding to the phenomenon producing the detected physio-anatomical change. The second to the penultimate letters represent the types and subtypes of the disease level, specifying the MRI technique used to acquire and detect the analysed information. The $\mathrm{D}(\mathrm{F})$ and $\mathrm{E}(\mathrm{D})$ level types are: unenhanced, dynamic or dynamic susceptibility contrast enhanced. Non-, light, and dark gray highlighted terms symbolise: unenhanced, dynamic, and dynamic susceptibility contrast enhanced MRI techniques respectively. Subtype refers to any new MRI technique subtype that can be introduced in the MCSSS in the future. The final letter represents the stage of the medical condition and also the RN_Parameter calculated. Negative values of the RN_Parameters are represented by underlined letters followed by underlined numbers. The numbers following the last letter in the configuration specifies the RN_Parameter value.

The ocular disease management strategy developed in this study is explained for the RN_Paramater value combination scenario presented in Table 3. These RN_Parameter values correspond to the hypothetical situation shown in Figure 2(b)). A hypothetical example of inflammation of the iris and ciliary body, and elastic deformations of the lens, and aqueous humour regions for $3 \mathrm{~T}$ human eye MRI is presented in Figure 2(b)). From all calculated RN_Parameter values, only $\mathrm{I}(\mathrm{R}(\mathrm{T} 2)) / \mathrm{D}(\mathrm{F}(\mathrm{f})) / \mathrm{E}(\mathrm{D}(\mathrm{T})) / \mathrm{E}(\mathrm{D}(\mathrm{V})) \quad$ RN_Parameters showed significant changes between the corresponding ocular regions evaluated in the DA and $\mathrm{CN}$ subjects in Table 3. The absolute values of these parameters are larger than the threshold value in this study: $50 \%$.

Table 3. Scenario of RN_Parameters in different eye structures visualised on 3 T MRI images. The $\mathrm{I}(\mathrm{R}(\mathrm{T} 2))$ and $\mathrm{D}(\mathrm{F}(\mathrm{f})) \mathrm{RN}$ _Paramater values in the vitreous humour, retina-choroid complex, and optic nerve regions presented below show that the $\mathrm{I}(\mathrm{R}(\mathrm{T} 2))$ and $D(F(f))$ values measured on the MRI images from the DA subject are significantly different compared to their corresponding $\mathrm{CN}$ values. The same is true for the $\mathrm{E}(\mathrm{D}(\mathrm{T})$ ) RN_Paramer values in the: iris, ciliary body, lens, and aqueous humour. All other RN_Parameter values calculated for the visualised ocular MRI structures are null, showing no significant changes between corresponding DA and CN RN_Paramater values. The MCSSS configuration is also specified for each ocular region.

\begin{tabular}{cccccc}
\hline \multirow{2}{*}{ Ocular region } & \multicolumn{3}{c}{ RN_Parameter value (\%) } & \multirow{2}{*}{ MCSSS configuration } \\
\cline { 2 - 4 } & \multicolumn{3}{c}{ Level(Type(RN_Parameter) } & \\
\cline { 2 - 4 } & $\mathrm{I}(\mathrm{R}(\mathrm{T} 2))$ & $\mathrm{D}(\mathrm{F}(\mathrm{f}))$ & $\mathrm{E}(\mathrm{D}((\mathrm{T}))$ & $\mathrm{E}(\mathrm{D}(\mathrm{V}))$ & \\
\hline vitreous humour & 92 & 156 & 0 & 0 & $\mathrm{I}(\mathrm{R}(\mathrm{T} 2(92))) ; \mathrm{D}(\mathrm{F}((\mathrm{f}(156)))$ \\
retina-choroid complex & 563 & 198 & 0 & 0 & $\mathrm{I}(\mathrm{R}(\mathrm{T} 2(563)) ; \mathrm{D}(\mathrm{F}((\mathrm{f}(198)))$ \\
optic nerve & -94 & 121 & 0 & 0 & $\mathrm{I}(\mathrm{R}(\underline{\mathrm{T} 2(94))}) ; \mathrm{D}(\mathrm{F}((\mathrm{f}(121)))$ \\
iris & 0 & 0 & 81 & 0 & $\mathrm{E}(\mathrm{D}(\mathrm{T}(81)))$ \\
ciliary body & 0 & 0 & 54 & 0 & $\mathrm{E}(\mathrm{D}(\mathrm{T}(54)))$ \\
lens & 0 & 0 & 0 & 65 & $\mathrm{E}(\mathrm{D}(\mathrm{V}(65)))$ \\
aqueous humour & 0 & 0 & 0 & -52 & $\mathrm{E}(\mathrm{D}(\mathrm{V}(52)))$ \\
\hline
\end{tabular}


The negative $\mathrm{I}(\mathrm{R}(\mathrm{T} 2))$ RN_Parameter calculated in the optic nerve region for positive $\mathrm{D}(\mathrm{F}(\mathrm{f})$ ) RN_Parameter values (Table 3 ), corresponds to broken blood vessels and blood-to-optic nerve barrier (Table 2). Harmful cells infiltrated the optic nerve through the blood stream and the disrupted blood-to-optic nerve barrier. They produced a more solid concentration of the optic nerve from the DA eye compared to the corresponding optic nerve region in the CN. This concentration decreased the $\mathrm{I}(\mathrm{R}(\mathrm{T} 2))$ value in the optic nerve region of the DA eye with $94 \%$ (Table 3), compared to the corresponding $\mathrm{CN} \mathrm{I}(\mathrm{R}(\mathrm{T} 2)$ ) values.

In the vitreous humour and retina-choroid complex regions, the $\mathrm{I}(\mathrm{R}(\mathrm{T} 2))$ and $\mathrm{D}(\mathrm{F}(\mathrm{f}))$ RN_Parameter values were positive (Table 3 ). This corresponds to a significant number of broken blood vessels in the vitreous humour and retina-choroid complex regions, but intact blood-to-: vitreous humour and retina-choroid complex barriers (Table 2). The intact barriers did not allow harmful cells enter the vitreous humour and retina-choroid complex regions through the blood stream. The blood spilled through the broken blood vessels produced an increased liquid concentration in the vitreous humour and retina-choroid complex regions. This determined an increase with $92 \%$ and $563 \%$ (Table 3) of the $\mathrm{I}(\mathrm{R}(\mathrm{T} 2)) \mathrm{RN} \_$Parameter values from the DA eye compared to the corresponding $\mathrm{CN}$ values in the vitreous humour and retina-choroid complex regions, respectively.

The events in the iris, ciliary body, lens, and aqueous humour, changed the ocular pressure in these regions, which produced a force applied on them and deformed them elastically. This corresponds to an increase of the $\mathrm{E}(\mathrm{D}(\mathrm{T})$ ) RN_Parameter values with $81 \%$ and $54 \%$ in the region of the iris and ciliary body, while for the lens and aqueous humour, the corresponding $\mathrm{E}(\mathrm{D}(\mathrm{V}))$ RN_Parameter values increased with 65 and decreased with 52\%, respectively. The MCSSS configurations of the eye condition in the vitreous humour, retina-choroid complex, optic nerve, iris, ciliary body, lens, and aqueous humour regions are also presented in Table 3.

Blood is supplied to the eye from the optic nerve [40]. If treatment is applied to stop or reduce the damage in the optic nerve region, it could be possible to regain the integrity of the aqueous humour, ciliary body, iris, lens, vitreous humour, and retina-choroid complex regions. If necessary, surgical intervention should be considered post optic nerve treatment to eliminate any remaining cellular infiltrates.

\section{Discussion}

Results in this study can easily and immediately be implemented in AI-based ocular MRI and demonstrate the feasibility of introducing AI-based analysis of ocular MRI scans. This could potentially support a program for the prevention and treatment of eye disease.

The research method developed and described here has three main compatibility areas: human anatomy, medical procedure, and imaging technique. The hMRI_PASC and MCSSS in this study have general human body applicability. 
The strategy for disease management is explained with the ocular MRI example, but it can be generalised to any organ. The research method developed in this study can be further developed to integrate all imaging techniques used at present in radiology. A similar approach to that presented here could be used to develop AI-based medical imaging strategies and extend the MCSSS for MRI in this study to: ultrasonography, computed tomography, positron emission tomography, laser or infrared medical imaging for example. The research method presented in this study is compatible with many medical procedures: diagnosis, prognosis, response to therapy, and surgery, for example. Once the generalisation to these three main compatibility areas has been achieved, software developers can integrate the research method in software for general human body AI-based medical imaging. This generalisation will answer the most important question for the need of standardised AI-based medical protocol implementation in medicine to tackle the socio-economic burden caused by disease worldwide [41] [42] [43].

Results in this study can also be customized and used immediately by medical specialists worldwide to increase the efficacy of their day-to-day practice, even before a general software for AI-based radiology is developed.

One limitation of this study is the need for the automatic medical condition prediction selection. This can be developed based on the as low as reasonably achievable principle, followed by a periodic testing-evaluation cycle, for example. Another important limitation is the evaluated subject role specification. Appropriate automated protocols should be developed to inform and obtain the correct informed consent from the evaluated subject before beginning any proposed medical procedure. All other ethical and legal aspects have to be clearly specified [44].

\section{Conclusion}

In conclusion, the hMRI_PASC, MCSSS, and disease management strategy in this study can be customized and implemented immediately by medical specialists in their day-to-day care practice for increased efficacy. This method can also be implemented immediately in software for AI-based MRI to further help medical specialists and reduce the socio-economical burden caused by disease. Results in this paper have applicability in the medical: diagnosis, prognosis, response to therapies, and/or surgery. Similar developments for other imaging techniques in radiology will generalise results in this study for the future possible implementation of standardised AI-based medical imaging.

\section{Acknowledgements}

Special thanks and thoughts are sent to all anonymous people always very happy and interested to contribute unconditionally to this evolution.

\section{Conflicts of Interest}

The author declares no conflicts of interest regarding the publication of this paper. 


\section{References}

[1] Fourcade, A. and Khonsari, R.H. (2019) Deep Learning in Medical Image Analysis: A Third Eye for Doctors. Journal of Stomatology, Oral and Maxillofacial Surgery. https://doi.org/10.1016/j.jormas.2019.06.002

[2] Langlotz, C.P., Allen, B., Erickson, B.J., Kalpathy-Cramer, J., Bigelow, K., Cook, T.S., Flanders, A.E., Lungren, M.P., Mendelson, D.S., Rudie, J.D., Wang, G. and Kandarpa, K. (2019) A Roadmap for Foundational Research on Artificial Intelligence in Medical Imaging: From the 2018 NIH/RSNA/ACR/the Academy Workshop. Radiology, 291, 781-791. https://doi.org/10.1148/radiol.2019190613

[3] Lin, S.Y., Mahoney, M.R. and Sinsky, C.A. (2019) Ten Ways Artificial Intelligence Will Transform Primary Care. Journal of General Internal Medicine, 34, 1626-1630. https://doi.org/10.1007/s11606-019-05035-1

[4] Gajanan, V.S., Wai, L.W. and Satnam, D. (2018) Application of Artificial Intelligence-Based Technology in Cancer Management: A Commentary on the Deployment of Artificial Neural Networks. Anticancer Research, 38, 6607-6607. https://doi.org/10.21873/anticanres.13027

[5] Senders, J.T., Staples, P.C., Karhade, A.V., Zaki, M.M., Gormely, W.B., Broekman, M.L.D, Smith, T.R. and Arnaout, O. (2018) Machine Learning and Neurosurgical Outcome Prediction: A Systematic Review. World Neurosurgery, 109, 476-486. https://doi.org/10.1016/j.wneu.2017.09.149

[6] Wandell, B.A. (2016) Clarifying Human White Matter. Annual Review of Neuroscience, 39, 103-128. https://doi.org/10.1146/annurev-neuro-070815-013815

[7] Wandell, B.A. and Winawer, J. (2015) Computational Neuroimaging and Population Receptive Fields. Trends in Cognitive Sciences, 6, 349-357.

https://doi.org/10.1016/j.tics.2015.03.009

[8] Wandell, B.A., Winawer, J. and Kay, N. (2015) Computational Modeling of Responses in Human Visual Cortex. Brain Mapping, 1, 651-659.

https://doi.org/10.1016/B978-0-12-397025-1.00347-X

[9] Benson, N.C., Butt, O.H., Datta, R., Radoeva, P.D., Brainard, D.H. and Aguirre, G.K. (2012) The Retinotopic Organization of Striate Cortex Is Well Predicted by Surface Topology. Current Biology, 22, 2081-2085.

https://doi.org/10.1016/j.cub.2012.09.014

[10] Benson, N.C., Butt, O.H., Brainard, D.H. and Aguirre, G.K. (2014) Correction of Distortion in Flattened Representations of the Cortical Surface Allows Prediction of V1-V3 Functional Organization from Anatomy. PLOS Computational Biology, 10, e1003538. https://doi.org/10.1371/journal.pcbi.1003538

[11] Benson, N.C., Jamison, K.W. and Arcaro, M.J. (2018) The Human Connectome Project 7 Tesla Retinotopy Dataset: Description and Population Receptive Field Analysis. Journal of Visualization, 18, 23. https://doi.org/10.1167/18.13.23

[12] Benson, N.C. and Winawer, J. (2018) Bayesian Analysis of Retinotopic Maps. eLife, 7, e40224. https://elifesciences.org/articles/40224 https://doi.org/10.7554/eLife.40224

[13] Jiang, H., Tian, Q., Farrell, J. and Wandell, B.A. (2017) Learning the Image Processing Pipeline. IEEE Transactions on Image Processing, 26, 5032-5042. https://doi.org/10.1109/TIP.2017.2713942

[14] Dumoulin, S.O. and Wandell, B.A. (2008) Population Receptive Field Estimates in Human Visual Cortex. Neuroimage, 39, 647-660. https://doi.org/10.1016/j.neuroimage.2007.09.034 
[15] Dumoulin, S.O., Harvey, B.M., Fracasso, A., Zuiderbaan, W., Luijten, P.R., Wandell, B.A. and Petridou, N. (2017) In Vivo Evidence of Functional and Anatomical Stripe-Based Subdivisions in Human V2 and V3. Scientific Reports, 7, Article No. 733. https://doi.org/10.1038/s41598-017-00634-6

[16] Poline, J.B., Breeze, J.L., Ghosh, S., Gorgolewski, K., Halchenko, Y.O., Hanke, M., Haselgrove, C., Helmer, K.G., Keator, D.B., Marcus, D.S., Poldrack, R.A., Scwartz, Y., Ashburner, J. and Kennedy, D.N. (2012) Data Sharing in Neuroimaging Research. Frontiers in Neuroinformatics, 6, 9. https://doi.org/10.3389/fninf.2012.00009

[17] Kovach, D. (2017) The Computational Theory of Intelligence: Feedback. International Journal of Modern Nonlinear Theory and Application, 6, 70-73. https://doi.org/10.4236/ijmnta.2017.62006

[18] Scott, A., Courtney, W., Wood, D., de la Garza, R., Lane, S., King, M., Wang, R., Roberts, J., Turner, J.A. and Calhoun, V.D. (2011) COINS: An Innovative Informatics and Neuroimaging Tool Suite Built for Large Heterogeneous Datasets. Frontiers in Neuroinformatics, 5, 33. https://doi.org/10.3389/fninf.2011.00033

[19] Kim, D.V., Jang, H.Y., Kim, K.W., Shin, Y. and Park, S.H. (2019) Design Characteristics of Studies Reporting the Performance of Artificial Intelligence Algorithms for Diagnostic Analysis of Medical Images: Results from Recently Published Papers. Korean Journal of Radiology, 20, 405-410. https://doi.org/10.3348/kjr.2019.0025

[20] Fanea, L. (2018) Reference 3 T MRI Parameters of the Normal Human Eye. Physica Medica, 47, 50-57. https://doi.org/10.1016/j.ejmp.2018.02.007

[21] Lommers, E., Simon, J., Reuter, G., Delrue, G., Dive, D., Degueldre, C., Balteau, E., Phillips, C. and Maquet, P. (2019) Multiparameter MRI Quantification of Microstructural Tissue Alterations in Multiple Sclerosis. NeuroImage: Clinical, 23, Article ID: 101879. https://doi.org/10.1016/j.nicl.2019.101879

[22] Shiohama, T., McDavid, J., Levman, J. and Takahashi, E. (2019) Quantitative Brain Morphological Analysis in CHARGE Syndrome. NeuroImage: Clinical, 23, Article ID: 101866. https://doi.org/10.1016/j.nicl.2019.101866

[23] Wetter, A., Nensa, F., Lipponer, C., Guberina, N., Olbricht, T., Schenck, M., Schlosser, T.W., Gratz, M. and Lauenstein, T.C. (2015) High and Ultra-High b-Value Diffusion-Weighted Imaging in Prostate Cancer: A Quantitative Analysis. Acta Radiologica, 56, 1009-1015. https://doi.org/10.1177/0284185114547900

[24] Boesen, L., Nørgaard, N., Løgager, V., Balslev, I. and Thomsen, H.S. (2018) Multiparametric MRI in Men with Clinical Suspicion of Prostate Cancer Undergoing Repeat Biopsy: A Prospective Comparison with Clinical Findings and Histopathology. Acta Radiologica, 59, 371-380. https://doi.org/10.1177/0284185117718400

[25] Sureka, B., Elhence, P., Khera, P.S., Choudhary, G.R., Pandey, H., Garg, P.K., Yadav, K. and Goel, A. (2019) Quantitative Contrast-Enhanced Perfusion Kinetics in Multiparametric MRI in Differentiating Prostate Cancer from Chronic Prostatitis: Results from a Pilot Study. The British Journal of Radiology, 92, Article ID: 20190181. https://doi.org/10.1259/bjr.20190181

[26] Cuocolo, R., Stanzione, A., Ponsiglione, A., Romeo, V., Verde, F., Creta, M., La Rocca, R., Longo, N. and Imbriaco, M. (2019) Clinically Significant Prostate Cancer Detection on MRI: A Radiomic Shape Features Study. European Journal of Radiology, 116, 144-149. https://doi.org/10.1016/j.ejrad.2019.05.006

[27] Seraphim, A., Knott, K.D., Augusto, J., Bhuva, A.N., Manisty, C. and Moon, J.C. (2019) Quantitative Cardiac MRI. Journal of Magnetic Resonance Imaging. https://doi.org/10.1002/jmri.26789 
[28] Ikebe, Y., Ishimaru, H., Imai, H., Abe, K., Izumo, T., Morofuji, Y., Ideguchi, R., Morikawa, M. and Uetani, M. (2019) Quantitative Susceptibility Mapping for Carotid Atherosclerotic Plaques: A Pilot Study. Magnetic Resonance in Medical Sciences. https://doi.org/10.2463/mrms.mp.2018-0077

[29] Santamaria, G., Bargallo, X., Ganau, S.G., Alonso, I., Muñoz, M., Mollà, M., Fernández, P.L. and Prat, A. (2019) Multiparametric MR Imaging to Assess Response Following Neoadjuvant Systemic Treatment in Various Breast Cancer Subtypes: Comparison between Different Definitions of Pathologic Complete Response. European Radiology, 117, 132-139. https://doi.org/10.1016/j.ejrad.2019.06.009

[30] Patz, S., Bert, R.J., Frederick, E. and Freddo, T.F. (2007) T1 and T2 Measurements of the Fine Structures of the in Vivo and Enucleated Human Eye. Journal of Magnetic Resonance Imaging, 26, 510-518. https://doi.org/10.1002/jmri.21017

[31] Richdale, K., Wassenaar, P., Bluestein, K.T., Abduljalil, A., Christoforidis, J.A., Lanz, T., Knopp, M.V. and Schmalbrock, P. (2009) 7 T MR Imaging of the Human Eye in Vivo. Journal of Magnetic Resonance Imaging, 30, 924-932. https://doi.org/10.1002/jmri.21959

[32] Fanea, L., David, L.I., Lebovici, A., Carbone, F. and Sfrangeu, S.A. (2012) Theoretical Compartment Modeling of DCE-MRI Data Based on the Transport across Physiological Barriers in the Brain. Computational and Mathematical Methods in Medicine, 2012, Article ID: 482565. https://doi.org/10.1155/2012/482565

[33] Tian, B. (2018) Building Artificial Intelligence for Dermatological Practice. Open Access Library Journal, 5, 1-6. https://doi.org/10.4236/oalib.1104541

[34] Tang, C., Wu, J. and Chen, R. (2018) A Method for Normal Direction Judge Applied in Electrocardiographic Problem. Journal of Biosciences and Medicines, 6, 1-8. https://doi.org/10.4236/jbm.2018.61001

[35] Markl, M., Schnell, S., Wu, C., Bollache, E., Jarvis, K., Barker, A.J., Robinson, J.D. and Rigsby, C.K. (2016) Advanced Flow MRI: Emerging Techniques and Applications. Clinical Radiology, 71, 779-795. https://doi.org/10.1016/j.crad.2016.01.011

[36] Haacke, E.M., Mittal, S., Wu, Z., Neelavalli, J. and Cheng, Y.C. (2009) Susceptibility-Weighted Imaging: Technical Aspects and Clinical Applications, Part 1. American Journal of Neuroradiology, 30, 19-30. https://doi.org/10.3174/ajnr.A1400

[37] Mariappan, Y.K., Glaser, K.J. and Ehman, R.L. (2010) Magnetic Resonance Elastography: A Review. Clinical Anatomy, 23, 497-511. https://doi.org/10.1002/ca.21006

[38] Zhang, Y., Nateras, O.S.E., Peng, Q., Kuranov, R.V., Harrison, J.M., Milner, T.E. and Duong, T.Q. (2011) Lamina-Specific Anatomic Magnetic Resonance Imaging of the Human Retina. Investigative Ophthalmology \& Visual Science, 52, 7232-7237. https://doi.org/10.1167/iovs.11-7623

[39] Baliyan, V., Das, C.J., Sharma, R. and Gupta, A.K. (2016) Diffusion Weighted Imaging: Technique and Applications. World Journal of Radiology, 8, 785-798. https://doi.org/10.4329/wjr.v8.i9.785

[40] Hart, W.M. (1992) Adler's Physiology of the Eye. 9th Edition, Mosby, St Louis.

[41] Pesapane, F., Codari, M. and Sardanelli, F. (2018) Artificial Intelligence in Medical Imaging: Threat or Opportunity? Radiologists Again at the Forefront of Innovation in Medicine. European Radiology Experimental, 2, 35-45.

https://doi.org/10.1186/s41747-018-0061-6

[42] Kobayashi, Y., Ishibashi, M. and Kobayashi, H. (2019) How Will "Democratization of Artificial Intelligence" Change the Future of Radiologists? Japanese Journal of Radiology, 37, 9-14. https://doi.org/10.1007/s11604-018-0793-5 
[43] Serreau, R. (2018) How to Pool Medical Services in Preventive Medicine Unit at 01/01/18 of Orléans Metropole/Orléans City Hall Structure: A Multi Disciplinary Network. Journal of Biosciences and Medicines, 6, 17-21.

https://doi.org/10.4236/jbm.2018.61003

[44] Pepito, J., Vasquez, B. and Locsin, R. (2019) Artificial Intelligence and Autonomous Machines: Influences, Consequences, and Dilemmas in Human Care. Health, 11, 932-949. https://doi.org/10.4236/health.2019.117075 